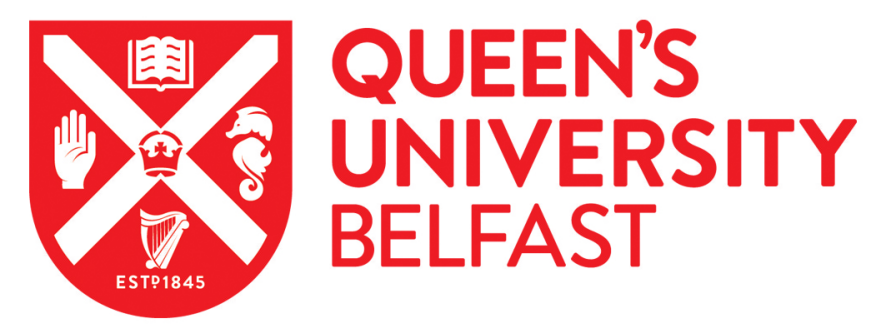

\title{
Hot-melt extrusion of photodynamic antimicrobial polymers for prevention of microbial contamination
}

Wylie, M. P., Irwin, N. J., Howard, D., Heydon, K., \& McCoy, C. P. (2021). Hot-melt extrusion of photodynamic antimicrobial polymers for prevention of microbial contamination. Journal of Photochemistry and Photobiology B: Biology, 214, [112098]. https://doi.org/10.1016/j.jphotobiol.2020.112098

Published in:

Journal of Photochemistry and Photobiology B: Biology

Document Version:

Peer reviewed version

Queen's University Belfast - Research Portal:

Link to publication record in Queen's University Belfast Research Portal

Publisher rights

(C) 2020 Elsevier B.V. All rights reserved..

This manuscript version is made available under the CC-BY-NC-ND 4.0 license http://creativecommons.org/licenses/by-nc-nd/4.0/,which permits distribution and reproduction for non-commercial purposes, provided the author and source are cited.

\section{General rights}

Copyright for the publications made accessible via the Queen's University Belfast Research Portal is retained by the author(s) and / or other copyright owners and it is a condition of accessing these publications that users recognise and abide by the legal requirements associated with these rights.

Take down policy

The Research Portal is Queen's institutional repository that provides access to Queen's research output. Every effort has been made to ensure that content in the Research Portal does not infringe any person's rights, or applicable UK laws. If you discover content in the Research Portal that you believe breaches copyright or violates any law, please contact openaccess@qub.ac.uk. 


\title{
Hot-melt extrusion of photodynamic antimicrobial polymers for prevention of microbial contamination
}

\author{
Matthew P. Wylie ${ }^{1}$, Nicola J. Irwin ${ }^{1}$, David Howard ${ }^{2}$, Katie Heydon ${ }^{2}$, Colin P. McCoy ${ }^{1 *}$ \\ ${ }^{1}$ School of Pharmacy, Queen's University Belfast, 97 Lisburn Road, Belfast, BT9 7BL, U.K. \\ ${ }^{2}$ IPC - Innovative Polymer Compounds, Midlands Gateway Business Park, Streamstown Road, \\ Kilbeggan, Co. Westmeath, Ireland. \\ * Corresponding author (c.mccoy@qub.ac.uk)
}

\section{Abstract:}

Infectious disease outbreaks within healthcare facilities can exacerbate patient illness and, in some cases, can be fatal. Contaminated surfaces and medical devices can act as a reservoir for transmission of pathogens and have been linked to the rising incidence of healthcareacquired infections. Antimicrobial surfaces can reduce microbial contamination and transmission and have emerged as a crucial component in healthcare infection control in recent years. The aim of this study was to manufacture antimicrobial polymer surfaces containing the photosensitiser, toluidine blue $\mathrm{O}(\mathrm{TBO})$, using hot-melt extrusion (HME). Several concentrations of TBO were combined with a range of medically relevant polymers via HME. TBO-polymer extrudates displayed no significant differences in thermal properties and surface wettability relative to non-loaded polymers. Minimal leaching of TBO from the surface was confirmed through in vitro release studies. Antibacterial activity was observed to vary according to the polymer and concentration of incorporated TBO, with PEBAX ${ }^{\circledR}$ polymers modified with $0.1 \% \mathrm{w} / \mathrm{w}$ TBO demonstrating promising reductions of $>99.9 \%$ in viable bacterial adherence of a range of common nosocomial pathogens, including Staphylococcus aureus, Staphylococcus epidermidis, Acinetobacter baumannii and Escherichia coli. This study demonstrates the use of HME as a facile alternative method to common encapsulation strategies for the production of light-activated antimicrobial polymer surfaces. This method can be easily translated to large-scale manufacture and, in addition, the polymers constitute promising antimicrobial base materials for the rapidly growing additive manufacturing industries.

Keywords: Hot-melt extrusion; photodynamic antimicrobial chemotherapy; toluidine blue O; infection control

\section{Introduction}

High levels of hospital hygiene are essential to prevent microbial transmission and reduce the incidence of healthcare-acquired infections (HAls). Whilst infection control measures have vastly improved over the last few decades, HAls remain a common and significant threat to 
patient health with a reported incidence of $\sim 6 \%$ in acute care hospitals in the UK ${ }^{1-3}$. One of the main reasons for this is the failure to eliminate microbial bioburden from within healthcare environments due to the constant cycling of patients, staff and visitors in and out of these environments, who each carry a unique microbiome. Studies have shown that the skin and nasal passages of healthy individuals commonly harbour pathogenic bacteria, such as MRSA, which can inadvertently be transmitted to patients through poor hand hygiene or contaminated surfaces ${ }^{4,5}$.

The importance of surface cleanliness in the prevention of HAls has recently been highlighted 6-8. Due to the large number of high-touch surfaces within hospital wards, such as medical equipment interfaces, patient documents, door handles and patient beds, it is not surprising that many of these surfaces constitute key reservoirs of bacteria $7,9,10$.

The development of antimicrobial or anti-adhesive surfaces capable of preventing survival of pathogenic microbes has been reported as a major breakthrough in controlling HAls ${ }^{11}$. Copper and silver surfaces have been incorporated into many aspects of the hospital environment, such as bed rails, counter-tops and sinks, and have been shown to reduce microbial contamination ${ }^{12}$. However, Muller et al. (2016) have highlighted that the majority of antimicrobial surfaces trialled to-date, based on copper, silver or nanoparticle technologies, are only suitable for metallic hospital surfaces or surfaces amenable to coating with metal/metal nanoparticles ${ }^{13}$. With many hospital furnishings, such as keyboards, textiles, desks and floors, commonly manufactured from polymers there exists an urgent need for alternative antimicrobial surface technologies which can be safely incorporated into polymeric materials.

Photosensitive agents constitute an attractive alternative to antimicrobial metals/metal oxides for the production of antimicrobial surfaces or coatings ${ }^{14}$. Photosensitive agents, such as porphyrin and phenothiazinium compounds, are light-activated agents that produce reactive oxygen species. They have been successfully utilised as photodynamic chemotherapy agents for treatment of various skin, oral and gastrointestinal carcinomas ${ }^{15}$. More recently, these agents have been increasingly used for antimicrobial applications in photodynamic antimicrobial chemotherapy (PACT), and have demonstrated clinical efficacy in eradicating mouth and skin infections ${ }^{16}$. We have previously reported the incorporation of porphyrins into hydrogel lenses to prevent intraocular lens infections ${ }^{17-19}$. Additionally, Perni et al. used similar 'shrink-swell' techniques to incorporate photosensitisers into silicone and polyurethane materials, which demonstrated resistance to Gram-positive and Gram-negative bacteria when irradiated with red laser light ${ }^{20-25}$. Porphyrins have also been covalently attached to cellulose cotton fabrics to reduce HAls associated with patient gowns and bed curtains ${ }^{26}$. While these materials have displayed promising antimicrobial activities, most have been produced through surface modification processes such as 'swell and shrink' or covalent binding of photosensitisers which can compromise physical properties or complicate scale-up for commercial applications due to additional costs, the need for solvent recovery and poor 
reproducibility. To aid the transfer of antimicrobial surface technologies into widespread healthcare applications, these factors must therefore be taken into consideration.

Hot-melt extrusion (HME) is a technology that is well established in the polymer industry for the production of plastic bags, pipes, food packaging, and polymer sheets and films. HME is an extremely simple and rapid method for the production of high volumes of uniform products. A schematic representation shown in Figure 1 outlines the steps of HME, beginning with feeding of polymer and drug components into the chamber (1), followed by melting of the polymer (and drug) (2) accompanied by polymer-drug mixing (3), resulting in the production of a homogenous drug-polymer conjugate (4), which is then extruded into a desired physical shape/form using a pre-selected exit die (5). Shapes can include tablets, films and rods which, if desired, can then be pelletised and re-melted to facilitate injection moulding or film-blowing to obtain the final product design.

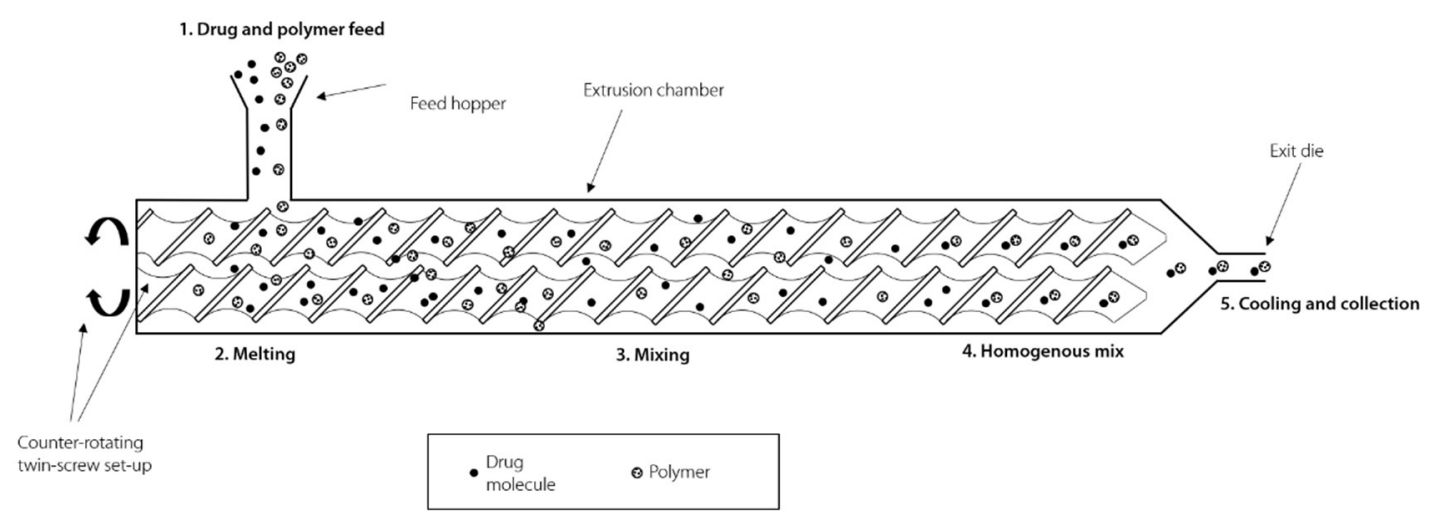

Figure 1. Schematic representation of polymer-drug mixing using counter rotating twin-screw hot-melt extruder.

While use of HME has traditionally been confined to the plastics industry, there has been increased interest in its pharmaceutical relevance, with HME demonstrated to be a useful alternative for the production of dosage forms and other drug delivery systems ${ }^{27-29}$. With respect to antimicrobial applications, there is a remarkable lack of research reporting on the combination of HME and antimicrobials for producing antimicrobial surfaces or medical device coatings, likely due to the low thermal stability of traditional antibiotics. Cassidy et al. (2011) developed a triggered release system using HME for the delivery of a photosensitiser to the colon ${ }^{30}$. While this study was clinically unsuccessful due to inadequate oxygenation within the colon for singlet oxygen generation, it demonstrated successful extrusion of a photosensitiser-incorporated polymer with no thermal degradation. We have subsequently reported the successful incorporation of photosensitisers into high-density polyethylene (HDPE) using HME. The prepared polymers demonstrated reductions in adherence of MRSA and $E$. coli by $>3-\log _{10}$ and $1.5-\log _{10}$, respectively, when irradiated with a halogen light source ${ }^{14}$. Similarly, Zema et al. (2010) have reported the manufacture of antimicrobial preservative packaging for cosmetic and pharmaceutical applications by mixing the preservative, dehydroacetic acid sodium salt (DHA.Na), with HDPE using HME to form a matrix which provided sustained release of DHA.Na upon contact with water, and released $>50 \%$ of 
preservative content after 30 days ${ }^{31}$. This study highlighted the potential of HME to produce scalable and tailored antimicrobial polymeric systems capable of prolonged release of antimicrobial agents.

With the increasing popularity of 3D printing/additive manufacture, the use of HME to produce antimicrobial filaments could facilitate the large scale production of antimicrobial polymers. Sandler et al. (2014) coupled HME with 3D printing to allow the one-step manufacture of medical devices with innate antibiofilm properties ${ }^{32}$. These initial studies on the incorporation of antimicrobials into polymeric products using HME highlight a promising approach for the production of antimicrobial medical devices and surfaces to help combat the risk of HAls.

Herein we report the successful incorporation of the photosensitiser, TBO, into a range of medically-relevant polymers using industrial-scale HME equipment. The thermal and surface wettability properties, leaching behaviour and antimicrobial performance of the TBOincorporated polymers when illuminated in white light against bacteria and fungi demonstrate that this technique can be used to produce antimicrobial surfaces to assist in the control of pathogen transmission within healthcare facilities. Potential applications for these light-activated materials are as surface coatings or bulk materials for infection-resistant medical devices, such as medical tubing, catheters and wearable technologies, or fomites, such as tubing, door handles and equipment enclosures.

\section{Results:}

\subsection{Thermal characterisation of toluidine blue O (TBO)}

An important consideration when using $\mathrm{HME}$ is that some polymers require high melting temperatures and/or screw speeds or pressure to be extruded successfully. These factors can limit the range of active pharmaceutical ingredients (APIs) which can be incorporated into the polymer due to thermal degradation or polymorphism during HME. The thermal stability of TBO was firstly assessed to determine the maximum permittable extrusion temperature for incorporation into polymers using HME (Figure 2). 


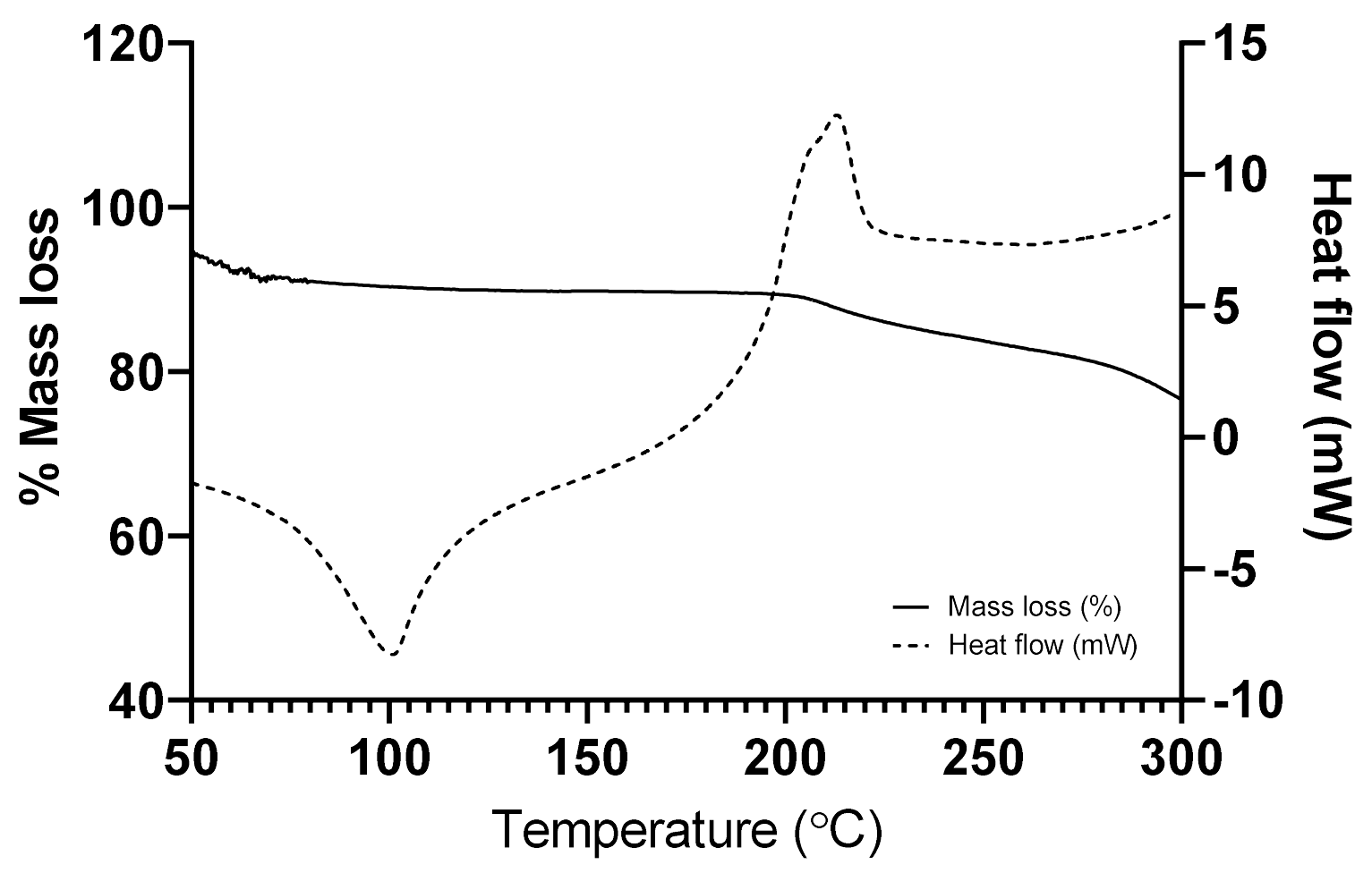

Figure 2. Thermal characterisation of toluidine blue $\mathrm{O}$ upon heating to $300^{\circ} \mathrm{C}$ at a heating rate of $10^{\circ} \mathrm{C} /$ minute.

The data in Figure 2 show an initial mass loss of $10 \%$ between $50-120^{\circ} \mathrm{C}$, which coincided with an exothermic peak at $100^{\circ} \mathrm{C}$ and was therefore attributed to loss of residual moisture. Thermal degradation of dry TBO was detected at $205^{\circ} \mathrm{C}$ and $5 \%$ mass loss of the initial dry mass $\left(\mathrm{T}_{95 \%}\right)$ was observed at $230^{\circ} \mathrm{C}$. Thus, it was determined that TBO could be safely extruded up to a maximum temperature of $\sim 200-220^{\circ} \mathrm{C}$, accounting for the additional factors, such as screw rotation, chamber pressure and residence time which could lead to increased heat exposure ${ }^{33}$.

\subsection{Hot-melt extrusion of TBO-incorporated polymers}

A number of medically-relevant polymer candidates, including polyether block amide (PEBA), acrylonitrile butadiene styrene (ABS), polyamide (Nylon), thermoplastic elastomer (TPE) and thermoplastic polyurethane (TPU), as listed in Table 1, were extruded with $0.05 \%, 0.075 \%$ and $0.1 \% \mathrm{w} / \mathrm{w}$ TBO loadings using a commercial Leistritz ZSE 27 MAXX - 40 L/D twin screw extruder and injection moulded into thin plaques. Images of the final polymeric materials are shown in Figure 3. 
Table 1. Details of polymers used to produce TBO-incorporated extrudates

\begin{tabular}{|l|l|}
\hline Polymer name & Polymer type \\
\hline PEBAX $^{\circledR} 2533$ & PEBA \\
\hline PEBA $^{\circledast} 7033$ & PEBA \\
\hline PEBAX $^{\circledast} 7233$ & PEBA \\
\hline Cycolac $^{\text {TM }}$ HMG 47 MD & ABS \\
\hline Rilsan $^{\circledast}$ BMNO & Nylon 11 \\
\hline Chemiton $^{\circledast}$ HMB NA80 & TPE \\
\hline Pellethane $^{\circledast} 2363-90 A$ & TPU \\
\hline
\end{tabular}

From Figure 3, it is evident that incorporation of TBO induced a blue pigmentation of each polymer and, as expected, the intensity of pigmentation increased with increasing TBO concentration. We have previously reported the incorporation of $0.4 \% \mathrm{w} / \mathrm{w}$ TBO into HDPE sheets to provide antimicrobial thin films for touch screens. Despite promising antimicrobial activity, the $0.4 \% \mathrm{w} / \mathrm{w}$ loading was found to produce TBO aggregates on film surfaces and to cause a dark purple pigmentation which affected usability ${ }^{14}$. Thus, in this study reduced loadings of $0.05-0.1 \% \mathrm{w} / \mathrm{w}$ TBO were investigated. From the images in Figure 3 it was evident that concentrations of $0.1 \% \mathrm{w} / \mathrm{w}$ TBO produced a blue pigmentation in all polymers but the intensity of this pigmentation depended largely on the visual properties of unmodified polymers. For example, incorporation of TBO into PEBA polymers produced a dark purple pigmentation with several small aggregates visible. In contrast, TBO extrudates produced with Chemiton ${ }^{\circledR}$ HMB NA80 and Cycolac ${ }^{\text {TM }}$ HMG 47 MD had a transparent pale blue appearance. All extrudates displayed evidence of small TBO aggregates within the polymer matrix (as highlighted by red arrows in Figure 3) which could indicate poor mixing or dissolution of TBO in the polymers, although the reduced incidence of aggregates in samples loaded with 0.05 $0.075 \% \mathrm{w} / \mathrm{w}$ TBO indicated that aggregate formation was related to TBO loading concentration. 

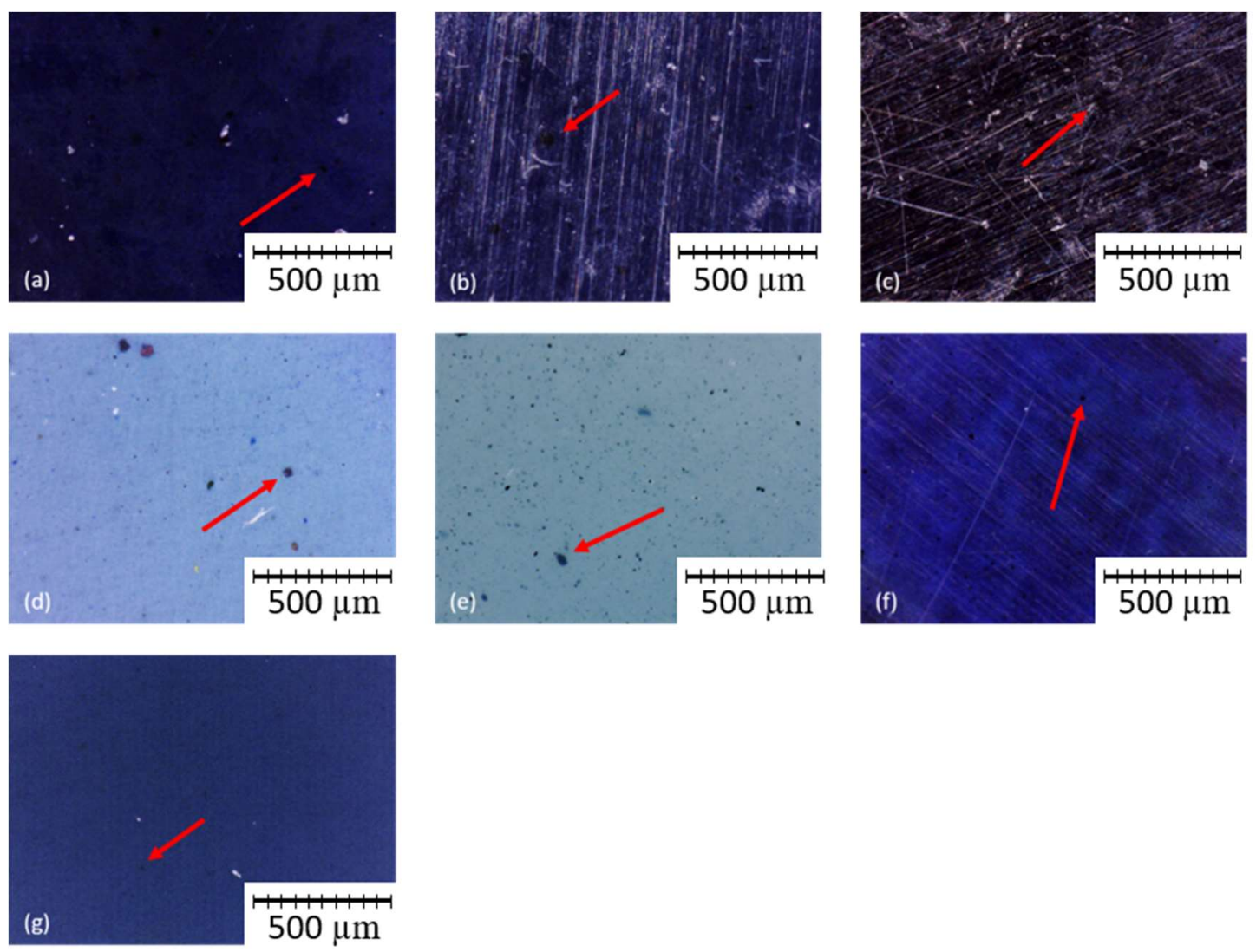

Figure 3. Digital surface imaging, at $x 200$, of $0.1 \% \mathrm{w} / \mathrm{w}$ TBO-loaded (a) PEBAX ${ }^{\circledR} 2533$, (b) PEBAX ${ }^{\circledR} 7033$, (c) PEBAX ${ }^{\circledR} 7233$, (d) Chemiton ${ }^{\circledR}$ NA80, (e) Cycolac ${ }^{\text {TM }}$ ABS, (f) Rilsan ${ }^{\circledR}$ BMNO and (g) Pellethane ${ }^{\circledR}$. Red arrows indicate presence of TBO agglomerates within the polymer.

\subsection{Characterisation of TBO extrudates}

The surface and bulk properties of TBO-modified polymers were assessed to establish if TBOincorporation would significantly affect their suitability for applications in which the base polymers are currently employed. Static water contact angles were determined for each polymer and are shown in Figure 4. 


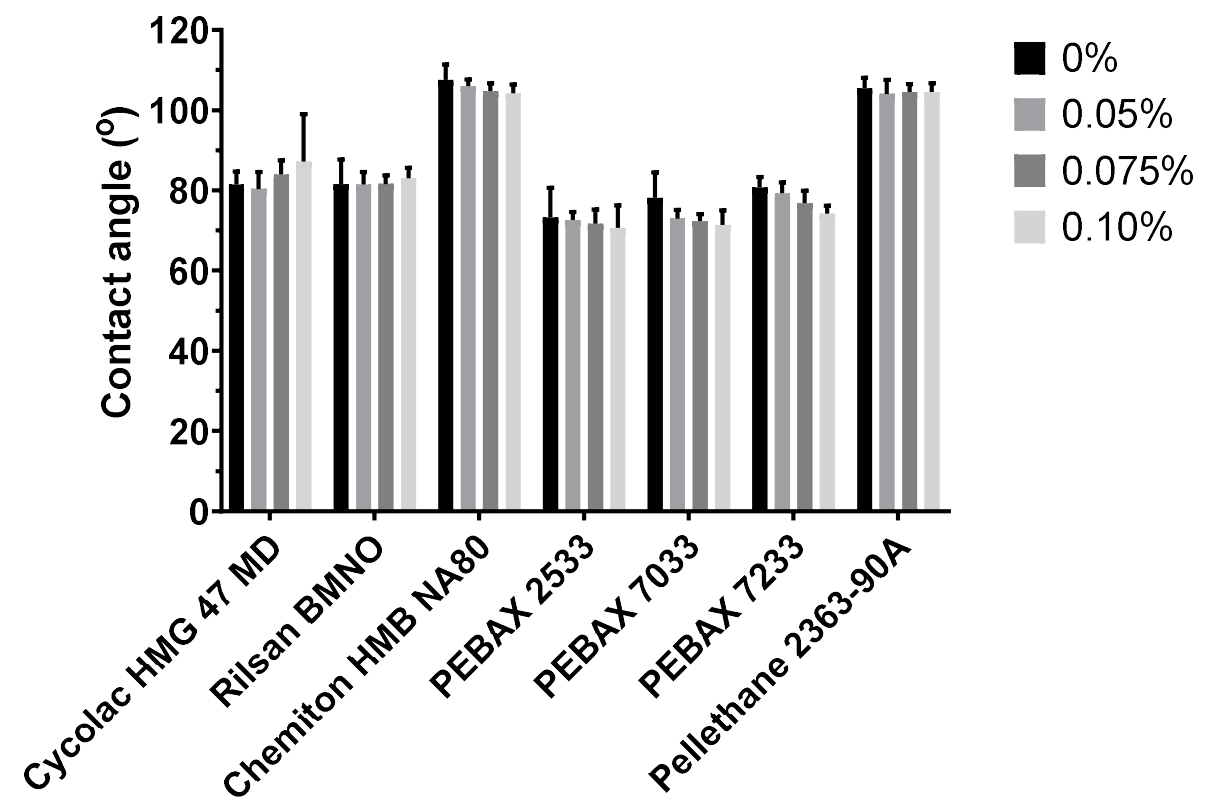

Figure 4. Static water contact angles of polymers modified with $0.05 \%, 0.075 \%$ and $0.1 \% \mathrm{w} / \mathrm{w}$ TBO ( $0 \% \mathrm{w} / \mathrm{w}$ represents unmodified control polymer). Error bars represent \pm S.D., $n=5$.

The data in Figure 4 show the change in water contact angle of polymers upon incorporation of up to $0.1 \% \mathrm{w} / \mathrm{w}$ TBO. No significant difference in wetting behaviour was detected for any of the polymers at all TBO concentrations, with most polymers displaying an insignificant decrease in contact angle with increasing TBO concentration. This decrease can be attributed to the presence of increasing amounts of hydrophilic TBO molecules on the polymer surface, in accordance with previous reports ${ }^{34,35}$.

Thermal analysis was also conducted using TGA and DSC to determine if the incorporation of TBO affected the thermal properties of the polymers. All polymers were demonstrated to be stable to $\geq 300^{\circ} \mathrm{C}$, except for Chemiton ${ }^{\circledR}$ HMB NA80 and Pellethane ${ }^{\circledR}$ 2363-90A with observed $\mathrm{T}_{95 \%}$ values at $252^{\circ} \mathrm{C}$ and $293^{\circ} \mathrm{C}$, respectively (Figure S1 \& S2). Furthermore, the addition of $0.1 \% \mathrm{w} / \mathrm{w}$ TBO had no significant impact on the melting points or glass transition temperatures of any of the polymers and the similar DSC thermograms for the modified and unmodified polymers indicated that TBO did not chemically interact with or affect polymer crystallinity ${ }^{36}$.

To assess the potential suitability of TBO extrudates for medical and food-contacting applications, leaching of TBO from polymers in aqueous and $20 \% \mathrm{v} / \mathrm{v}$ ethanol solutions, to represent contact with hydrophilic and lipophilic media/food, respectively, was determined using UV-visible spectroscopy at $636 \mathrm{~nm}$ and results are shown in Figure 5. 
(a)

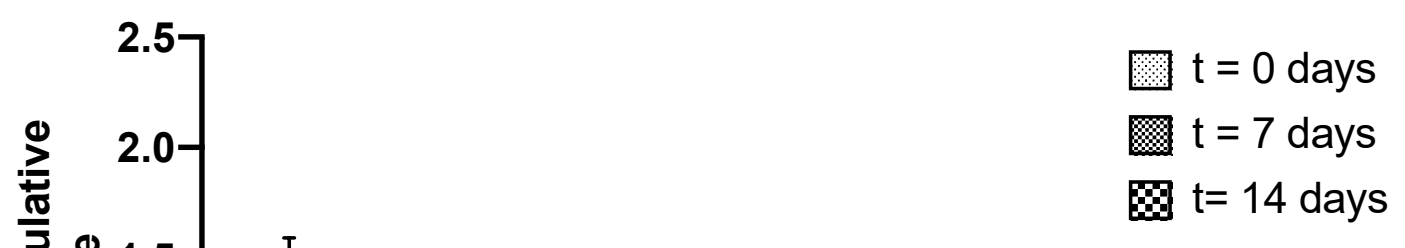

(b)

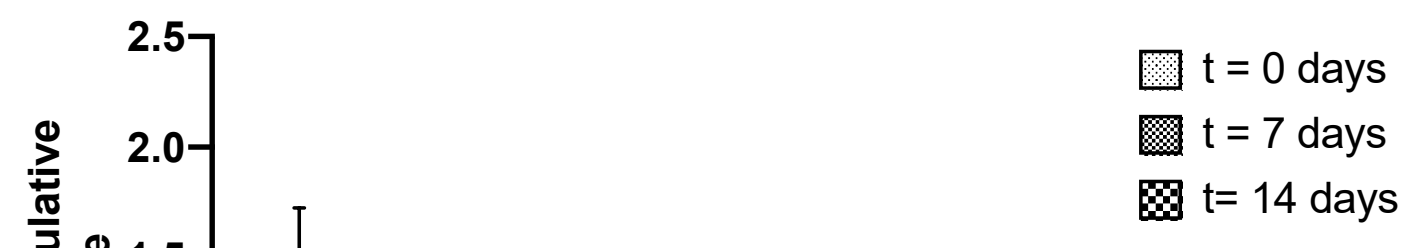


Figure 5. Cumulative percentage release of TBO from $0.1 \% \mathrm{w} / \mathrm{w}$ TBO polymers after immersion in (a) aqueous and (b) $20 \% \mathrm{v} / \mathrm{v}$ ethanol for periods up to 14 days. Error bars represent \pm S.D., $n=5$.

The data in Figure 5 show that TBO release from Pellethane ${ }^{\circledR}$ 2363-90A, Rilsan ${ }^{\circledR}$ BMNO and Cycolac $^{\mathrm{TM}}$ HMG 47 MD was negligible in both media over 14 days incubation. Furthermore, comparing TBO release in each media, no significant differences in release from $0.1 \% \mathrm{w} / \mathrm{w}$ TBO polymers was observed. In addition, increasing TBO concentration from $0.05 \%$ to $1 \% \mathrm{w} / \mathrm{w}$ caused no significant changes in TBO release in either media for all polymers except PEBAX 2533 which displayed significantly higher TBO release at $0.1 \% \mathrm{w} / \mathrm{w}$ loading. PEBAX ${ }^{\circledR}$ polymers and Chemiton ${ }^{\circledR}$ NA80 were demonstrated to release small amounts of TBO, with the highest release of $1.44 \%$ and $1.51 \%$ from $\mathrm{PEBAX}^{\circledR} 2533$ in aqueous and ethanolic conditions, respectively, after 14 days. This release of $\sim 1.5 \%$ TBO from PEBAX ${ }^{\circledR} 2533$, equated to an average TBO concentration of $3 \mathrm{mg} / \mathrm{L}$ (Table S1 \& S2). Overall, this data suggests that leaching of TBO from extruded polymers was minimal in both media, which is promising for potential use in medical or food-contacting applications, such as plastic packaging or tubing.

\subsection{Antimicrobial assessment of TBO extrudates}

Initial antimicrobial assessment of TBO extrudates was performed by challenging samples with the Gram-positive $S$. aureus. The reduction in viable $S$. aureus cells on TBO extrudates after irradiation in white light at ambient temperature is shown in Figure 6. As shown, PEBAX ${ }^{\circledR}$ 2533 was the most effective polymer against $S$. aureus, with $0.05 \%, 0.075 \%$ and $0.1 \% \mathrm{w} / \mathrm{w}$ TBO variants achieving respective reductions in viable bacterial adherence relative to control of $90.67 \%, 94.18 \%$ and $99.9 \%$ after $4 \mathrm{~h}$ irradiation. Similarly, Chemiton ${ }^{\circledR}$ NA80 loaded with $0.05 \%, 0.075 \%$ and $0.1 \% \mathrm{w} / \mathrm{w}$ TBO reduced numbers of adherent cells by $94.73 \%, 78.22 \%$ and 98.73\%, respectively. Overall, PEBAX ${ }^{\circledR} 2533$, PEBAX $^{\circledR} 7033$ and Chemiton ${ }^{\circledR}$ NA80 loaded with $0.1 \% \mathrm{w} / \mathrm{w}$ TBO provided the most significant reductions in viable bacterial adherence relative to control and were carried forward for further antimicrobial investigation. 
(a)

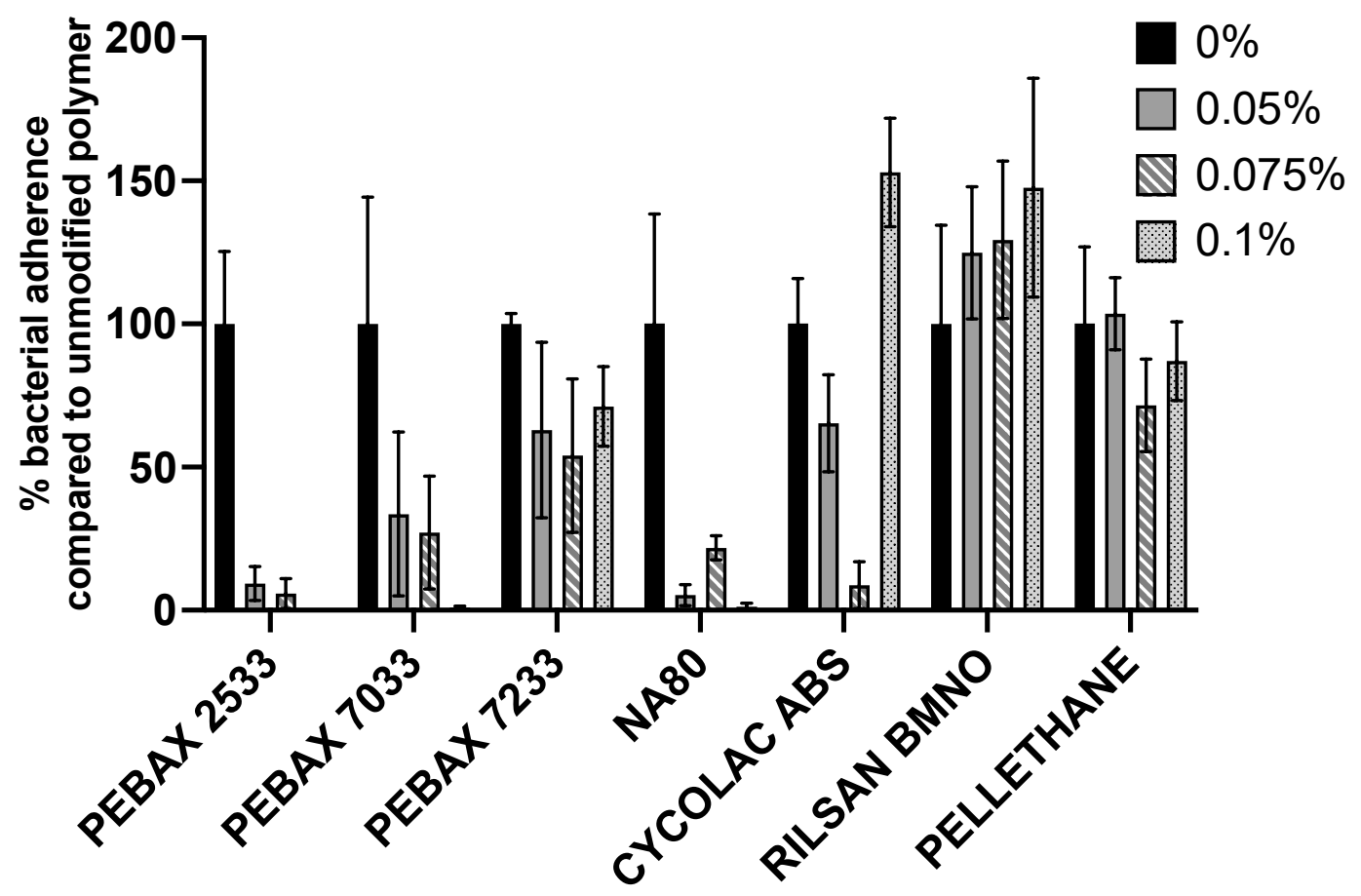

(b)

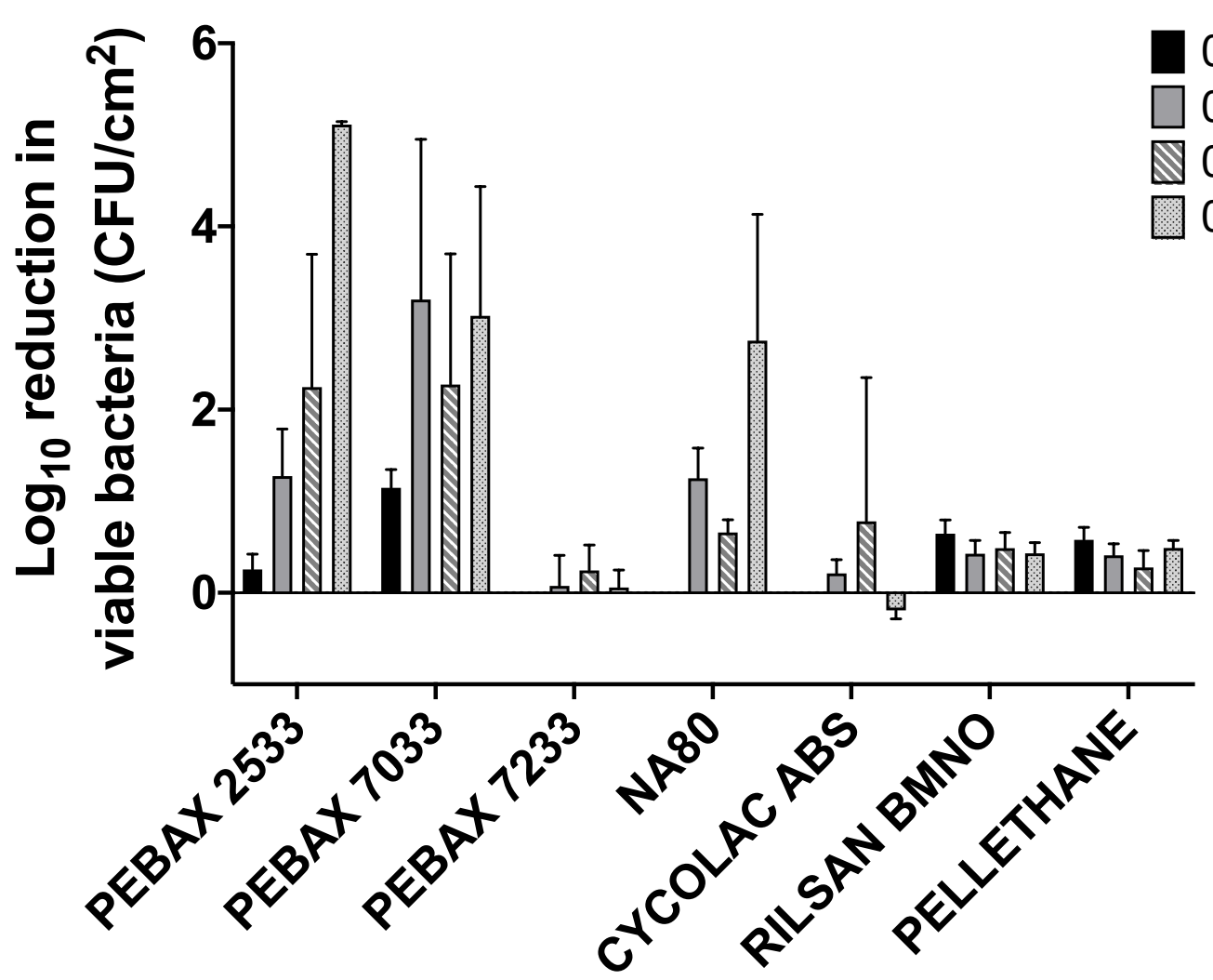

Figure 6. Antimicrobial efficacy of TBO-incorporated polymers challenged with $10^{6} \mathrm{cfu} / \mathrm{mL} \mathrm{S}$. aureus for $4 \mathrm{~h}$ under white LED irradiation at room temperature. Data is presented as (a) \% viable bacteria after $4 \mathrm{~h}$ irradiation relative to unmodified polymer (O\% TBO) and (b) $\log _{10}$ 
reduction in viable bacteria on surfaces exposed to light for $4 \mathrm{~h}$ relative to surfaces incubated in dark conditions.

Figure 7 shows the effect of TBO-incorporated PEBAX ${ }^{\circledR} 2533$, PEBAX ${ }^{\circledR} 7033$ and Chemiton $^{\circledR}$ NA80 on the adherence of viable S. epidermidis, A. baumannii, E. coli and C. albicans when irradiated for $4 \mathrm{~h}$ with white light at ambient temperature. When challenged with $S$. epidermidis, PEBAX $^{\circledR} 2533$ and Chemiton ${ }^{\circledR}$ NA80 achieved eradication of $>99.9 \%$ of viable cells at all TBO concentrations, whereas a loading of $0.1 \% \mathrm{w} / \mathrm{w}$ TBO was needed for this level of eradication with $\mathrm{PEBAX}{ }^{\circledR}$ 7033. In contrast, $\mathrm{PEBAX}{ }^{\circledR} 2533$ was the only polymer to display significant antimicrobial effects against the Gram-negative bacteria, A. baumannii and $E$. coli, achieving $>99 \%$ reduction in viable cells at all TBO concentrations. PEBAX ${ }^{\circledR} 7033$ and Chemiton ${ }^{\circledR} \mathrm{NA} 80$ failed to display any significant reduction in adherence of Gram-negative bacteria and adherence was, in contrast, promoted at lower TBO concentrations relative to the control polymer.

(a)

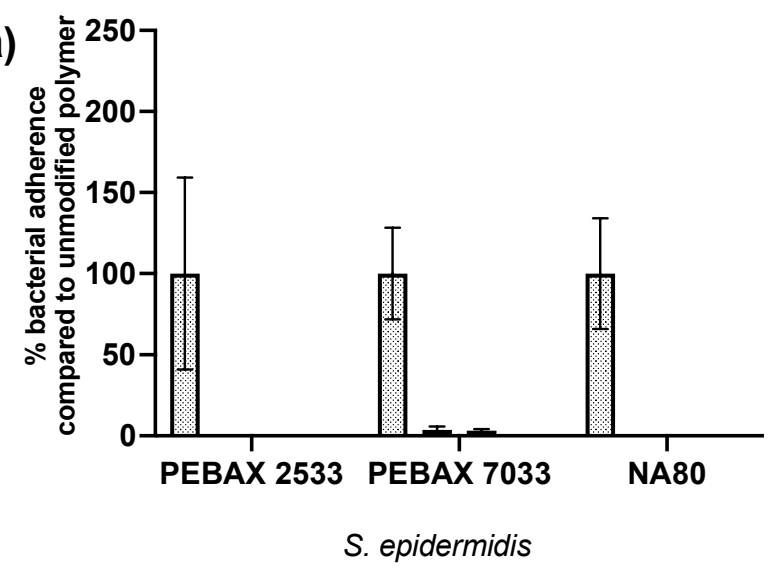

(c)

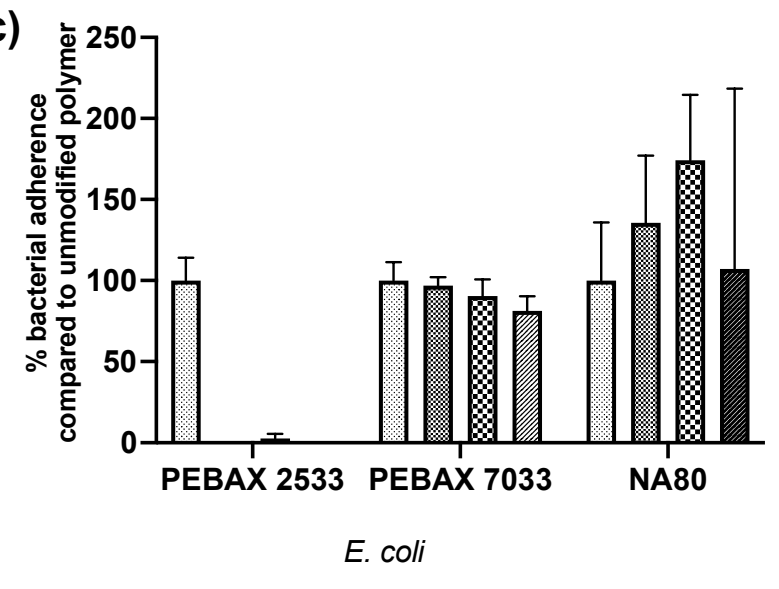

(b)

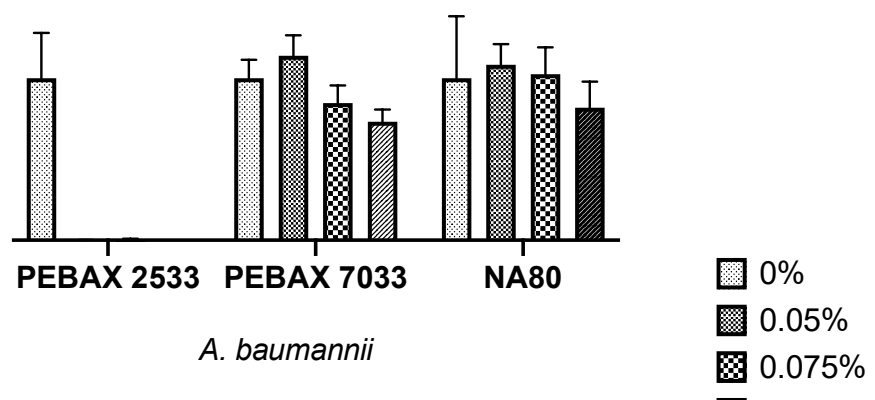

(d)

Figure 7. Antimicrobial efficacy of TBO-incorporated polymers challenged with $10^{6} \mathrm{cfu} / \mathrm{mL}$ of (a) S. epidermidis, (b) A. baumannii, (c) E. coli, and (d) C. albicans for $4 \mathrm{~h}$ under white LED irradiation at room temperature.

As shown in Figure $7(\mathrm{~d})$, both TBO-incorporated $\mathrm{PEBAX}{ }^{\circledR}$ polymers failed to reduce adherence of $C$. albicans relative to control after $4 \mathrm{~h}$ irradiation with white light, while TBO-modified Chemiton ${ }^{\circledR}$ NA80 achieved an insignificant reduction in adherence of $25-30 \%$. The relative 
reduction in microbial viability on TBO-incorporated polymer surfaces when irradiated with white light compared to storage in dark conditions is shown in Figure 8 . The data in Figure 8 further highlights the potent activity of the polymers against Gram-positive bacteria, with PEBAX 2533 displaying broad-spectrum activity at all tested TBO concentrations.

(a)

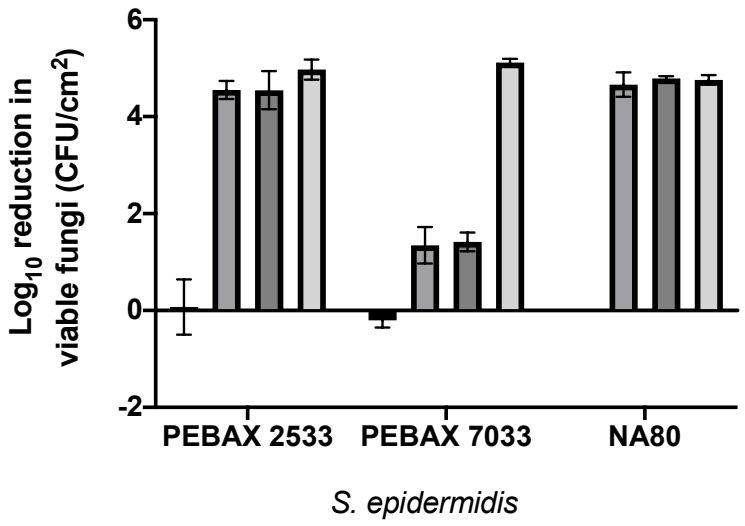

(c)

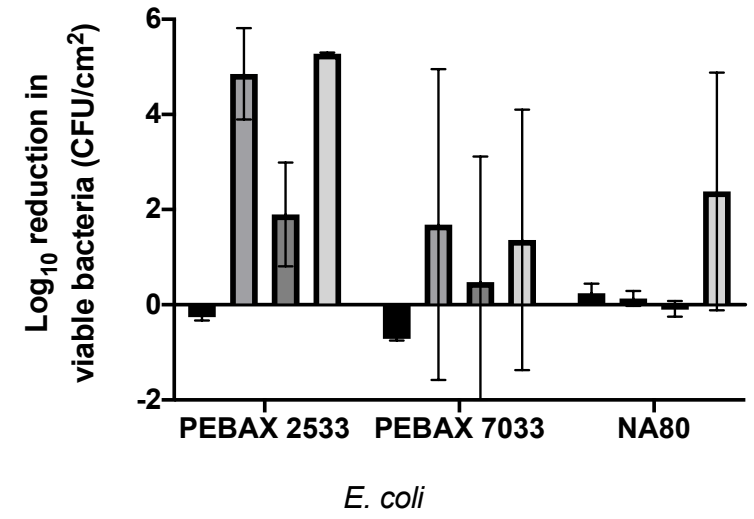

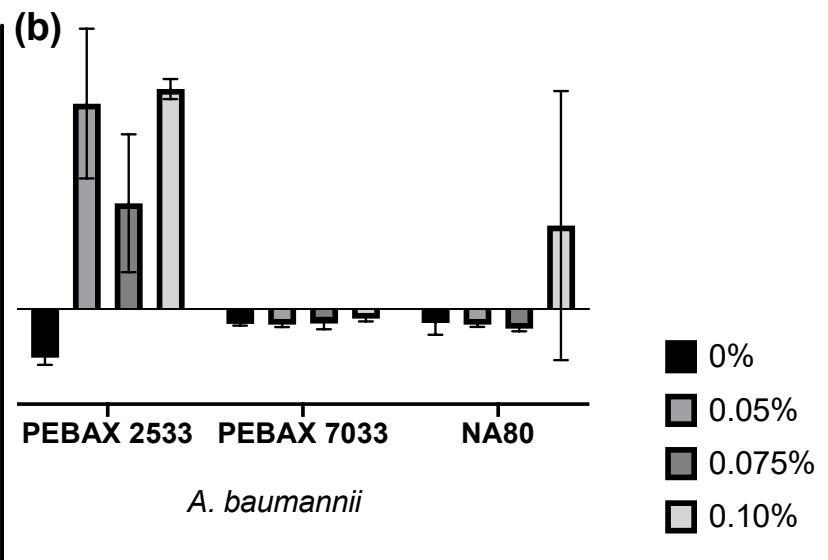

(d)

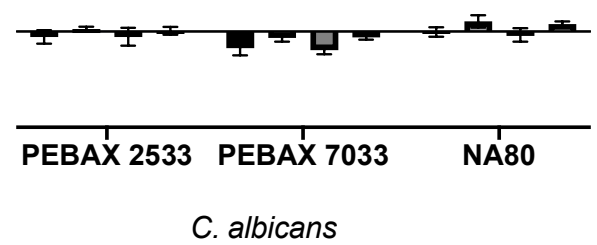

C. albicans

Figure 8. Reduction in microbial viability by TBO-incorporated polymers when irradiated with white light for $4 \mathrm{~h}$, relative to control samples kept in darkness, when challenged with $10^{6}$ $\mathrm{cfu} / \mathrm{mL}$ inoculum of (a) S. epidermidis, (b) A. baumannii, (c) E. coli, and (d) C. albicans.

\section{Discussion}

TBO, an antimicrobial photosensitiser, was herein incorporated into a series of polymers by HME with the aim of producing a contact-killing antimicrobial polymer surface. Photosensitiser agents can illicit an antimicrobial effect through the light-mediated generation of reactive oxygen species, such as singlet oxygen, which can oxidise important intra- and extracellular components of pathogenic cells leading to cell death and have been shown to effectively eradicate bacteria, bacterial spores, fungi and viruses ${ }^{37-41}$. HME has 
gained increasing popularity for the manufacture of pharmaceuticals due to its ease of use and versatility in the preparation of homogeneous polymer-drug composites which can be further modified with injection moulding or 3D-printing 42, 43. Previous strategies for immobilisation of TBO within polymeric materials for antimicrobial applications have relied upon the use of solvents or covalent functionalisation which can cause adverse effects on the polymer physical properties, such as tensile strength and wettability. The additional processing steps and complexity over standard polymer manufacturing processes for medical devices and other polymeric products are also undesirable ${ }^{17-25}$. HME was therefore investigated in this study as a method for the production of antimicrobial TBO polymers of a desired shape or, alternatively, to be pelletised for use in injection moulding or 3D-printing without loss of function or detrimental effects on the polymer properties or processing, thus overcoming the limitations of previously reported methods for light-activated antimicrobial surface production. An important consideration when using HME is the heat stability of a compound as it must be able to tolerate the high temperatures and shear usually required to melt common polymers, which can be up to $100-300^{\circ} \mathrm{C}$. In this study, it was found that TBO could withstand temperatures of up to $230^{\circ} \mathrm{C}$ without significant degradation and at this temperature TBO could be successfully incorporated into a range of different medical polymer classes. We have previously reported significant TBO aggregation upon incorporation of $0.4 \% \mathrm{w} / \mathrm{w}$ TBO into HDPE polymers. In this study we aimed to use a lower concentration of TBO to promote improved mixing. It was, however, evident that reduced TBO loadings still resulted in some TBO aggregation, but to a much lower extent, suggesting that concentrations may need to be kept $<0.1 \% \mathrm{w} / \mathrm{w}$ to facilitate complete dissolution and homogeneous mixing within each polymer and reduce potential effects on optical clarity. Conversely, this could also indicate the need for increased mixing time to ensure complete TBO dissolution ${ }^{44}$. The presence of TBO within the extruded polymers did not adversely affect their thermal stability. Furthermore, the intensity of endothermic peaks remained largely unchanged following incorporation of TBO, indicating TBO did not affect polymer crystallinity. The absence of any significant shifts in exothermic or endothermic peaks confirmed that TBO did not chemically interact with the polymers ${ }^{36}$. Non-significant reductions in surface water contact angles upon incorporation of TBO, caused by the weakly hydrophilic nature of TBO molecules situated on the surface as previously reported, are promising with regards to use of these TBO-modified polymers in fluid-contacting applications, such as those in which the base polymers are currently employed ${ }^{34,35}$.

An important consideration when producing polymeric materials with incorporated antibacterial agents for medical and non-medical applications, such as food packaging, is that the active compounds should not be released into the surrounding environment as acute or chronic exposure could have adverse effects on the health of users or the environment. There has been extensive media coverage of major incidents where leaching of dangerous packaging components into food or medicinal products has caused harm to, or even death of, users, such as the leaching of bisphenol A (BPA) from polycarbonate plastics commonly used to manufacture baby products including feeding bottles and spoons ${ }^{45}$. High temperatures and washing in detergent were found to allow BPA to subsequently leach into the contents of feeding bottles, with long-term exposure to BPA linked to endocrine disruption, estrogenic 
activity and growth suppression in infants, resulting in a ban of BPA in products intended for infants. Leaching of polymer additives can be enhanced by exposure to heat, lipophilic and aqueous fluids, and mechanical pressure ${ }^{46}$. Due to the clear risks posed by migration of potentially toxic chemicals into foodstuffs, the European Commission has produced guidelines to regulate the use of active or intelligent materials, such as antimicrobial packaging, in food-contacting applications and state that migration of non-authorised substances must be below $0.01 \mathrm{mg} / \mathrm{kg}^{47,48}$.

In this study, leaching of TBO into aqueous media and $20 \% \mathrm{v} / \mathrm{v}$ ethanol was used to simulate leaching when in contact with foods/liquids of mainly hydrophilic nature and more organic, lipophilic foods, respectively, and in all cases migration of TBO was below the permitted limit according to the EU Regulation No 450/2009 48, 49. Exposure to fluid would also be common upon use of these polymers in medical applications, such as medical surface furnishings. Of the polymers assessed, PEBAX ${ }^{\circledR}$ polymers and Chemiton ${ }^{\circledR}$ NA80 demonstrated higher TBO release in both media than $\mathrm{Cycolac}^{\mathrm{TM}}$, Rilsan $^{\circledR}$ and Pellethane ${ }^{\circledR}$ polymers, which displayed negligible release after 14 days. Furthermore, the extent of TBO release was not dependent on concentration, with no significant difference detected between released amounts from polymers with $0.05 \%, 0.75 \%$ and $0.1 \% \mathrm{w} / \mathrm{w}$ TBO loadings. The absence of a concentrationdependent release profile suggests that the extruded polymers acted as a reservoir-type surface which controlled the rate of release, with resultant release dependent on multiple factors, such as surface concentration, polymer thickness or permeability ${ }^{50}$. As the size of the samples used in the experiment were kept constant, release of TBO was therefore controlled by polymer permeability, with Chemiton ${ }^{\circledR}$ NA80 and PEBAX ${ }^{\circledR}$ polymers more permeable, or swellable, in water than the other three polymers.

TBO has been commonly used for photodynamic antimicrobial therapy and has been shown to be effective against bacteria when formulated in a solution or deposited onto a solid support ${ }^{51,52}$. TBO has been commonly immobilised onto polymer surfaces by solvent-casting methods whereby the polymer and TBO are dissolved in an aqueous solvent and then evaporated to dryness 53,54 . Other approaches such as swell-encapsulation or covalent immobilisation of photosensitisers have also been reported to provide successful lighttriggered antimicrobial surfaces, although these strategies suffer from photosensitiser leaching or require multiple surface modification steps $20,21,55$.

In this study, $\mathrm{PEBAX}^{\circledR} 2533, \mathrm{PEBAX}^{\circledR} 7033$ and Chemiton ${ }^{\circledR}$ NA80 polymers loaded with $\mathrm{TBO}$ achieved a statistically significant reduction in $\mathrm{S}$. aureus viability after $4 \mathrm{~h}$ irradiation. Of these three polymers, $\mathrm{PEBAX}{ }^{\circledR} 2533$ produced a considerably more potent effect, reducing viability beyond the limit of detection $(<100 \mathrm{cfu} / \mathrm{mL}$ ) when loaded with $0.1 \% \mathrm{w} / \mathrm{w}$ TBO. These results correlated with the extent of TBO leaching in aqueous media, with Chemiton ${ }^{\circledR}$ NA80, PEBAX ${ }^{\circledR}$ 2533 and $\mathrm{PEBAX}{ }^{\circledR} 7033$ shown to leach more TBO than the polymers which displayed limited efficacy against $S$. aureus. In addition, TBO-PEBAX ${ }^{\circledR} 2533$ had the most hydrophilic surface of the tested polymers. Since the microbiological assessment involved placing a $100 \mu \mathrm{L}$ drop of aqueous inoculum suspension in the centre of a $10 \times 10 \mathrm{~mm}$ sample, it is possible that the more hydrophilic surface of PEBAX ${ }^{\circledR}$ allowed increased spreading of the inoculum over the surface which may have brought $S$. aureus cells into contact with more TBO molecules. This effect has 
previously been described by Sellenet et al. (2007) who demonstrated that hydrophilic modification of quaternised poly(vinylpyridine) improved its antimicrobial efficacy by 20 -fold 56 . This was reported to be caused by the spreading of inoculum on high energy hydrophilic surfaces in contrast to the observed beading on low energy hydrophobic surfaces leading to increased and decreased bacterial contact with the bactericide, respectively. Upon further antimicrobial assessment of PEBAX $^{\circledR}$ 2533, PEBAX ${ }^{\circledR} 7033$ and Chemiton ${ }^{\circledR}$ NA80 against microbes commonly linked with skin colonisation and cross-contamination in hospitals, each polymer demonstrated activity against $S$. epidermidis, with $0.1 \%$ TBO w/w capable of achieving $>99.9 \%$ reduction in adherent cells after $4 \mathrm{~h}$. In contrast, when challenged with the Gram-negative bacteria, A. baumannii and E. coli, only PEBAX ${ }^{\circledR} 2533$ displayed significant antimicrobial efficacy. This supports the finding that the efficacy of these polymers is governed by the extent of TBO release or diffusion to the surface through polymer swelling. However, TBO leaching studies showed that while PEBAX polymers exhibited the highest release of TBO after 14 days, this accounted for less than 1.5\% of total TBO loading. Therefore, if slow release of TBO is a governing factor in the antimicrobial efficacy of these polymers it is likely the polymers can provide a long-term antimicrobial surface given the slow rate of TBO release in aqueous conditions.

The reduced antimicrobial efficacy of PEBAX $^{\circledR} 7033$ and Chemiton ${ }^{\circledR}$ NA80 against $A$. baumannii and E. coli relative to the Gram-positive pathogens was also attributed to the additional layer of lipopolysaccharide (LPS) in Gram-negative bacterial cell membranes. The decreased efficacy of TBO against Gram-negative bacteria, as a result of the reduced damage caused by TBO-generated singlet oxygen, has been previously reported ${ }^{57}$. Dahl et al. (1989) have shown that the initial susceptibility of bacteria to singlet oxygen is dependent on the cell wall structure, with the outer LPS layer of Gram-negative bacteria providing protection from extracellular singlet oxygen. Repeated attack of the LPS by singlet oxygen, however, results in generation of toxic peroxy radicals which cause lethal damage to the bacteria ${ }^{58}$. Thus, the absence of release of TBO from PEBAX ${ }^{\circledR} 7033$ and NA80, coupled with the low surface concentration of TBO, likely resulted in insufficient singlet oxygen production to cause significant damage to the bacteria.

C. albicans is a fungal species commonly associated with catheter-associated urinary tract infections (CAUTIs) and central-line-associated septicaemia. Candida species were also found to be the tenth most common cause of healthcare-associated infections in Scottish NHS hospitals in $2016^{57,59}$. Therefore, it is important that an antimicrobial surface is also assessed for its antifungal abilities to ensure adequate protection against the most common microbes found in healthcare. Similar to Gram-negative bacteria, the lack of effect of TBO-incorporated polymers against $C$. albicans can be attributed to the fungal cell structure. The presence of a nuclear membrane protects against singlet oxygen damage, with higher doses of photosensitisers, $\geq 2 \mathrm{mg} / \mathrm{mL}$, or increased light intensity, $\sim 200 \mathrm{~J} / \mathrm{cm}^{2}$, required to produce $>99 \%$ killing 54,60,61. Furthermore, the greater cell size and reduced number of targets available for singlet oxygen on the nuclear membrane have also been linked to this reduced susceptibility ${ }^{62}$. The antimicrobial efficacy of most of the polymers assessed in this study requires further optimisation to provide a significant benefit in infection control applications. The polymers in this study were irradiated with low-wattage white LED lights at ambient 
temperature to replicate real-world conditions and as such the lack of antimicrobial efficacy may be due to inefficient singlet oxygen production at the polymer surface in this environment. Future studies will investigate the effect of different irradiation conditions on antimicrobial efficacy, such as the use of portable light arrays which would still be feasible for real-world translation, and the addition of plasticisers to improve dissolution of TBO within high-melt polymers. Furthermore, there is potential for bacterial biofilm development on these surfaces in the absence of light, prior to PDT. Therefore, future studies will investigate the efficacy of these surfaces against developing biofilms to further assess their potential to eradicate bacterial fouling.

Overall, this study has demonstrated that HME can be successfully used for the incorporation of an antimicrobial photosensitiser into a range of medically relevant polymers without deleterious effects on the bulk polymer properties or degradation of the antimicrobial agent. In particular, the incorporation of $0.1 \% \mathrm{w} / \mathrm{w}$ TBO into PEBAX ${ }^{\circledR} 2533$ resulted in significant resistance to bacterial colonisation upon exposure to ambient light conditions, although further optimisation of other polymers tested in this study is required to achieve similar efficacy. The use of HME could provide a facile method to facilitate large-scale production of antimicrobial polymers for direct moulding into medical equipment or to provide antimicrobial filaments for the growing additive manufacturing industry.

\section{Experimental Section}

\subsection{Materials}

Toluidine Blue O (80\%) (TBO) was obtained from Sigma Aldrich (Poole, UK). PEBAX ${ }^{\circledR} 2533$ SA01, PEBAX ${ }^{\circledR} 7033$ SA01, PEBAX ${ }^{\circledR} 7233$ SA01, Chemiton ${ }^{\circledR}$ NA80, Pellethane ${ }^{\circledR}$ 2363-90A, Cycolac $^{\text {TM }}$ HMG47MD and Rilsan ${ }^{\circledR}$ BMNO were kindly supplied by IPC - Innovative Polymer Compounds (Kilbeggan, Ireland) in pelletised form or as $9 \times 6 \mathrm{~cm}$ injection moulded plaques.

Phosphate-buffered saline (PBS), Nutrient broth (NB), Sabouraud-dextrose broth (SDB), Mueller-Hinton broth (MHB), Nutrient agar (NA), Sabouraud-dextrose agar (SDA) and Mueller-Hinton Agar (MHA) were supplied by Oxoid Ltd. (Basingstoke, UK). S. aureus ATCC 6538, S. epidermidis ATCC 35984, A. baumannii NCTC 13304, E. coli ATCC 11303, Pseudomonas aeruginosa PA01 and Candida albicans NCYC 610 were stored on cryopreservative beads at $-80^{\circ} \mathrm{C}$ until use.

\subsection{Methods}


4.2.1 Preparation of photosensitiser-incorporated polymers using industrial extrusion and injection moulding machinery

Polymers were pelletised and mixed with TBO at IPC - Innovative Polymer Compounds (Kilbeggan, Ireland) and loaded into a Leistritz ZSE 27 MAXX - 40 L/D twin screw extruder to produce TBO-incorporated polymer rods with $0.05 \%, 0.075 \%$ and $0.1 \% \mathrm{w} / \mathrm{w}$ TBO loadings. TBO-incorporated rods were then pelletised, and injection moulded to form $9 \times 6 \mathrm{~cm}$ polymer plaques.

\subsubsection{Optical microscopy}

Samples were characterised using a Keyence VHX-2000E microscope (Keyence, Milton Keynes, UK), fitted with a VH-Z100R zoom lens. Samples were examined up to 1000x magnification and composite images captured using the Keyence microscopy software to allow accurate visualisation of surface features.

\subsubsection{Thermal analysis}

Differential scanning calorimetry (DSC) analysis of polymers and TBO was conducted using a Thermal Advantage Model Q100 DSC (TA Instruments, UK), equipped with a refrigerated cooling system. Polymer samples of 5-10 mg were crimped between an aluminium pan and lid and heated at $10^{\circ} \mathrm{C} / \mathrm{min}$ under a nitrogen purge $(50 \mathrm{~mL} / \mathrm{min})$ from $25^{\circ} \mathrm{C}$ to $300^{\circ} \mathrm{C}$. An empty crimped aluminium pan and lid was used as a reference cell.

Thermogravimetric analysis (TGA) was carried out using a Thermal Advantage Model Q500 TGA (TA Instruments, UK). Samples were heated at a rate of $10^{\circ} \mathrm{C} / \mathrm{min}$ from $25^{\circ} \mathrm{C}$ to $300^{\circ} \mathrm{C}$, and mass loss subsequently plotted as a function of increasing temperature.

\subsubsection{Water contact angle analysis}

Static water contact angle measurements were determined using a Biolin Theta Tensiometer (Manchester, UK) and 28 images captured over a two sec period initiated upon contact of the water droplet with the sample surface. Contact angle measurements were taken as the mean contact angle after one sec of stabilisation on the sample surface. A $4 \mu \mathrm{L}$ droplet of deionised water was used as the wetting agent.

\subsubsection{Leaching of TBO from extruded TBO-polymers}

Leaching studies were conducted in either PBS or $20 \% \mathrm{v} / \mathrm{v}$ aqueous ethanol solutions to represent aqueous or lipid-rich media, respectively, based on previous literature ${ }^{49} .10 \mathrm{~mm} \mathrm{x}$ $10 \mathrm{~mm}$ samples of each polymer were placed in clean glass McCartney bottles and submerged with $5 \mathrm{~mL}$ of either diluent. Media was replaced on a weekly basis and samples taken from the spent media. These samples were analysed using UV-spectroscopy at $610 \mathrm{~nm}$ and checked against a TBO calibration curve for each media (aqueous $\mathrm{r}^{2}=0.992 ; 20 \% \mathrm{v} / \mathrm{v}$ ethanol 
$\left.r^{2}=0.998\right)$ to determine overall TBO release. A minimum of 5 replicates were tested for each polymer and samples were placed in a dark cupboard at ambient temperature during studies.

\subsubsection{Antimicrobial assessment}

Antimicrobial assessment was based on previously reported methods evaluating contact-kill ability of copper and dry surfaces ${ }^{63,64} .10 \times 10 \mathrm{~mm}$ polymer samples were cleaned in deionised water for 1 minute and allowed to dry. Samples were then aseptically placed on a sterile petri-dish. $10^{6} \mathrm{cfu} / \mathrm{mL}$ bacterial suspensions of $S$. aureus, S. epidermidis, A. baumannii, E. coli or C. albicans in PBS were prepared and $100 \mu \mathrm{L}$ of suspension placed on each sample 30 minutes before irradiation with white LED light for $4 \mathrm{~h}$. The 30 minute pre-irradiation period was chosen to allow the droplet to settle and spread on the surface, thereby ensuring maximum contact with the photosensitiser-incorporated surface prior to irradiation with the light source. After $4 \mathrm{~h}$, samples were placed in $5 \mathrm{~mL}$ QSRS in tin-foil wrapped McCartney bottles and sonicated for 10 minutes. QSRS solutions were then serially diluted and $20 \mu \mathrm{L}$ plated on MHA (S. aureus, S. epidermidis, A. baumannii), NA plates (E. coli) or SDA (C. albicans) and incubated for 24-48 h. Viable cells were counted using the Miles and Misra technique ${ }^{65}$. Irradiation was conducted at room temperature with an adjustable white LED array (Flolight $^{\mathrm{TM}}$, Microbeam 1024 daylight spot, Markertek, UK) containing 1024 individual white LED lights in a square array. The LED array was held $12 \mathrm{~cm}$ above the irradiated samples to provide a power density of $6.57 \mathrm{mw} / \mathrm{cm}^{2}(450-700 \mathrm{~nm})$ and fluence rate of $94.6 \mathrm{~mJ} / \mathrm{cm}^{2}$ to an illuminated area of $30 \times 30 \mathrm{~cm}$

\subsubsection{Statistical analysis}

Statistical analysis was carried out using GraphPad Prism 8 statistical software. Release of TBO from polymers was analysed using two-way ANOVA with Tukey's multiple comparisons test. Analysis of water contact angles and antimicrobial efficacy of individual polymers was carried out using one-way ANOVA with Tukey's multiple comparisons test, while intra-polymer variations were analysed using a two-way ANOVA. The number of replicates $(n)$ tested was five and statistical significance was denoted as $p<0.05$.

\section{Conflicts of interest}

There are no conflicts of interest to declare.

\section{Acknowledgements:}


We thank IPC - Innovative Polymer Compounds (Kilbeggan, Ireland) for the supply of polymer materials and development of a compounding method.

This work was supported by the Enterprise Ireland Innovation programme (voucher IV-20163259) and the Innovate UK/HEFCE ICURe Innovation to Commercialisation of University Research Programme.

\section{Supplementary information:}

Contains TGA/DSC thermograms and cumulative TBO release data in $\%$ and $\mathrm{mg} / \mathrm{mL}$ TBO concentrations of TBO-incorporated polymers

\section{Author information:}

\section{Corresponding Author}

Colin P. McCoy - School of Pharmacy, Queen's University Belfast, 97 Lisburn Road, Belfast, BT9 7BL, U.K.; https://orcid.org/0000-0002-6468-2018; Email: c.mccoy@qub.ac.uk

$\underline{\text { Authors }}$

Matthew P. Wylie - School of Pharmacy, Queen's University Belfast, 97 Lisburn Road, Belfast, BT9 7BL, U.K.; https://orcid.org/0000-0002-7402-7092

Nicola J. Irwin - School of Pharmacy, Queen's University Belfast, 97 Lisburn Road, Belfast, BT9 7BL, U.K.; https://orcid.org/0000-0003-1336-3823

David Howard - IPC - Innovative Polymer Compounds, Midlands Gateway Business Park, Streamstown Road, Kilbeggan, Co. Westmeath, Ireland.

Katie Heydon - IPC - Innovative Polymer Compounds, Midlands Gateway Business Park, Streamstown Road, Kilbeggan, Co. Westmeath, Ireland.

\section{References:}

1. Suetens, C.; Latour, K.; Kärki, T.; Ricchizzi, E.; Kinross, P.; Moro, M. L.; Jans, B.; Hopkins, S.; Hansen, S.; Lyytikäinen, O., Prevalence of healthcare-associated infections, estimated incidence and composite antimicrobial resistance index in acute care hospitals and long-term care facilities: results from two European point prevalence surveys, 2016 to 2017. Eurosurveillance 2018, 23 (46). 2. Public Health Wales, National Point Prevalence Surveyof Healthcare Associated Infection, Device Usage and AntimicrobialPrescribing 2017 - Wales. 2018.

3. Public Health Agency, Northern Ireland Point Prevalence Survey of Hospital Associated infections and Antimicrobial Use, 2017. Public Health Agency, 2018.

4. Khan, H. A.; Baig, F. K.; Mehboob, R., Nosocomial infections: Epidemiology, prevention, control and surveillance. Asian Pacific Journal of Tropical Biomedicine 2017, 7 (5), 478-482. 
5. Güçlü, E.; Yavuz, T.; Tokmak, A.; Behçet, M.; Karali, E.; Öztürk, Ö.; Egeli, E., Nasal carriage of pathogenic bacteria in medical students: effects of clinic exposure on prevalence and antibiotic susceptibility. European Archives of Oto-Rhino-Laryngology 2007, 264 (1), 85-88.

6. Otter, J. A.; Yezli, S.; French, G. L., The role of contaminated surfaces in the transmission of nosocomial pathogens. In Use of biocidal surfaces for reduction of healthcare acquired infections, Springer: 2014; pp 27-58.

7. Weinstein, R. A.; Hota, B., Contamination, Disinfection, and Cross-Colonization: Are Hospital Surfaces Reservoirs for Nosocomial Infection? Clin. Infect. Dis. 2004, 39 (8), 1182-1189.

8. Boyce, J. M., Environmental contamination makes an important contribution to hospital infection. Journal of hospital infection 2007, 65, 50-54.

9. Russotto, V.; Cortegiani, A.; Raineri, S. M.; Giarratano, A., Bacterial contamination of inanimate surfaces and equipment in the intensive care unit. Journal of Intensive Care 2015, 3 (1), 54.

10. Kramer, A.; Schwebke, I.; Kampf, G., How long do nosocomial pathogens persist on inanimate surfaces? A systematic review. BMC infectious diseases 2006, 6 (1), 130.

11. Dancer, S. J., Controlling hospital-acquired infection: focus on the role of the environment and new technologies for decontamination. Clin Microbiol Rev 2014, 27 (4), 665-690.

12. Karpanen, T. J.; Casey, A. L.; Lambert, P. A.; Cookson, B. D.; Nightingale, P.; Miruszenko, L.; Elliott, T. S. J., The Antimicrobial Efficacy of Copper Alloy Furnishing in the Clinical Environment: A Crossover Study. Infect. Control Hosp. Epidemiol. 2012, 33 (1), 3-9.

13. Muller, M. P.; MacDougall, C.; Lim, M., Antimicrobial surfaces to prevent healthcareassociated infections: a systematic review. J Hosp Infect 2016, 92 (1), 7-13.

14. McCoy, C. P.; O’Neil, E. J.; Cowley, J. F.; Carson, L.; De Baróid, Á. T.; Gdowski, G. T.; Gorman, S. P.; Jones, D. S., Photodynamic Antimicrobial Polymers for Infection Control. PLOS ONE 2014, 9 (9), e108500.

15. Craig, R. A.; McCoy, C. P.; Gorman, S. P.; Jones, D. S., Photosensitisers - the progression from photodynamic therapy to anti-infective surfaces. Expert opinion on drug delivery 2015, 12 (1), 85-101.

16. Dai, T.; Huang, Y.-Y.; Hamblin, M. R., Photodynamic therapy for localized infections--state of the art. Photodiagnosis Photodyn Ther 2009, 6 (3-4), 170-188.

17. Brady, C.; Bell, S. E. J.; Parsons, C.; Gorman, S. P.; Jones, D. S.; McCoy, C. P., Novel Porphyrin-Incorporated Hydrogels for Photoactive Intraocular Lens Biomaterials. The Journal of Physical Chemistry B 2007, 111 (3), 527-534.

18. Parsons, C.; McCoy, C. P.; Gorman, S. P.; Jones, D. S.; Bell, S. E. J.; Brady, C.; McGlinchey, S. M., Anti-infective photodynamic biomaterials for the prevention of intraocular lens-associated infectious endophthalmitis. Biomaterials 2009, 30 (4), 597-602.

19. McCoy, C. P.; Craig, R. A.; McGlinchey, S. M.; Carson, L.; Jones, D. S.; Gorman, S. P., Surface localisation of photosensitisers on intraocular lens biomaterials for prevention of infectious endophthalmitis and retinal protection. Biomaterials 2012, 33 (32), 7952-8.

20. Perni, S.; Prokopovich, P.; Piccirillo, C.; Pratten, J.; Parkin, I. P.; Wilson, M., Toluidine bluecontaining polymers exhibit potent bactericidal activity when irradiated with red laser light. Journal of Materials Chemistry 2009, 19 (18), 2715-2723.

21. Perni, S.; Piccirillo, C.; Pratten, J.; Prokopovich, P.; Chrzanowski, W.; Parkin, I. P.; Wilson, $M$., The antimicrobial properties of light-activated polymers containing methylene blue and gold nanoparticles. Biomaterials 2009, 30 (1), 89-93.

22. Perni, S.; Prokopovich, P.; Parkin, I. P.; Wilson, M.; Pratten, J., Prevention of biofilm accumulation on a light-activated antimicrobial catheter material. Journal of Materials Chemistry 2010, 20 (39), 8668-8673.

23. Perni, S.; Pratten, J.; Wilson, M.; Piccirillo, C.; Parkin, I. P.; Prokopovich, P., Antimicrobial Properties of Light-activated Polyurethane Containing Indocyanine Green. Journal of Biomaterials Applications 2009, 25 (5), 387-400. 
24. Noimark, S.; Dunnill, C. W.; Kay, C. W. M.; Perni, S.; Prokopovich, P.; Ismail, S.; Wilson, M.; Parkin, I. P., Incorporation of methylene blue and nanogold into polyvinyl chloride catheters; a new approach for light-activated disinfection of surfaces. Journal of Materials Chemistry 2012, 22 (30), 15388-15396.

25. Noimark, S.; Bovis, M.; MacRobert, A. J.; Correia, A.; Allan, E.; Wilson, M.; Parkin, I. P., Photobactericidal polymers; the incorporation of crystal violet and nanogold into medical grade silicone. RSC Advances 2013, 3 (40), 18383-18394.

26. Ringot, C.; Sol, V.; Barrière, M.; Saad, N.; Bressollier, P.; Granet, R.; Couleaud, P.; Frochot, C.; Krausz, P., Triazinyl Porphyrin-Based Photoactive Cotton Fabrics: Preparation, Characterization, and Antibacterial Activity. Biomacromolecules 2011, 12 (5), 1716-1723.

27. Crowley, M. M.; Feng, Z.; Repka, M. A.; Thumma, S.; Upadhye, S. B.; Battu, S. K.; McGinity, J. W.; Martin, C., Pharmaceutical Applications of Hot-Melt Extrusion: Part I. Drug Development \& Industrial Pharmacy 2007, 33 (9), 909-926.

28. Chokshi, R. J.; Sandhu, H. K.; Iyer, R. M.; Shah, N. H.; Malick, A. W.; Zia, H., Characterization of physico-mechanical properties of indomethacin and polymers to assess their suitability for hotmelt extrusion processs as a means to manufacture solid dispersion/solution. Journal of pharmaceutical sciences 2005, 94 (11), 2463-2474.

29. Liu, X.; Lu, M.; Guo, Z.; Huang, L.; Feng, X.; Wu, C., Improving the chemical stability of amorphous solid dispersion with cocrystal technique by hot melt extrusion. Pharmaceutical research 2012, 29 (3), 806-817.

30. Cassidy, C. M.; Tunney, M. M.; Caldwell, D. L.; Andrews, G. P.; Donnelly, R. F., Development of Novel Oral Formulations Prepared via Hot Melt Extrusion for Targeted Delivery of Photosensitizer to the Colon. Photochem. Photobiol. 2011, 87 (4), 867-876.

31. Zema, L.; Sangalli, M. E.; Maroni, A.; Foppoli, A.; Bettero, A.; Gazzaniga, A., Active packaging for topical cosmetic/drug products: a hot-melt extruded preservative delivery device. Eur J Pharm Biopharm 2010, 75 (2), 291-6.

32. Sandler, N.; Salmela, I.; Fallarero, A.; Rosling, A.; Khajeheian, M.; Kolakovic, R.; Genina, N.; Nyman, J.; Vuorela, P., Towards fabrication of 3D printed medical devices to prevent biofilm formation. Int J Pharm 2014, 459 (1-2), 62-4.

33. Patil, H.; Tiwari, R. V.; Repka, M. A., Hot-Melt Extrusion: from Theory to Application in Pharmaceutical Formulation. AAPS PharmSciTech 2016, 17 (1), 20-42.

34. Sridharan, G.; Shankar, A. A., Toluidine blue: A review of its chemistry and clinical utility. J Oral Maxillofac Pathol 2012, 16 (2), 251-5.

35. Hwang, G. B.; Noimark, S.; Page, K.; Sehmi, S.; Macrobert, A. J.; Allan, E.; Parkin, I. P., White light-activated antimicrobial surfaces: effect of nanoparticles type on activity. Journal of Materials Chemistry B 2016, 4 (12), 2199-2207.

36. El-Houssiny, A.; Ward, A.; Mostafa, D.; Abd-El-Messieh, S.; Abdel-Nour, K.; Darwish, M.; Khalil, W., Drug-polymer interaction between glucosamine sulfate and alginate nanoparticles: FTIR, DSC and dielectric spectroscopy studies. Advances in Natural Sciences: Nanoscience and Nanotechnology 2016, 7 (2), 025014.

37. Souza, R. C.; Junqueira, J. C.; Rossoni, R. D.; Pereira, C. A.; Munin, E.; Jorge, A. O. C., Comparison of the photodynamic fungicidal efficacy of methylene blue, toluidine blue, malachite green and low-power laser irradiation alone against Candida albicans. Lasers in Medical Science 2010, 25 (3), 385-389.

38. Floyd, R. A.; Schneider, J. E.; Dittmer, D. P., Methylene blue photoinactivation of RNA viruses. Antiviral research 2004, 61 (3), 141-151.

39. Demidova, T. N.; Hamblin, M. R., Photodynamic Inactivation of <em >Bacillus</em> Spores, Mediated by Phenothiazinium Dyes. Appl Environ Microb 2005, 71 (11), 6918-6925.

40. Sharma, M.; Visai, L.; Bragheri, F.; Cristiani, I.; Gupta, P. K.; Speziale, P., Toluidine BlueMediated Photodynamic Effects on Staphylococcal Biofilms. Antimicrobial agents and chemotherapy 2008, 52 (1), 299-305. 
41. Komerik, N.; Wilson, M., Factors influencing the susceptibility of Gram-negative bacteria to toluidine blue O-mediated lethal photosensitization. Journal of applied microbiology 2002, 92 (4), 618-23.

42. Maniruzzaman, M.; Boateng, J. S.; Snowden, M. J.; Douroumis, D., A Review of Hot-Melt Extrusion: Process Technology to Pharmaceutical Products. ISRN Pharmaceutics 2012, 2012, 9.

43. Zhang, J.; Feng, X.; Patil, H.; Tiwari, R. V.; Repka, M. A., Coupling 3D printing with hot-melt extrusion to produce controlled-release tablets. Int J Pharm 2017, 519 (1-2), 186-197.

44. McCoy, C. P.; O'Neil, E. J.; Cowley, J. F.; Carson, L.; De Baroid, A. T.; Gdowski, G. T.; Gorman, S. P.; Jones, D. S., Photodynamic antimicrobial polymers for infection control. PLoS One 2014, 9 (9), e108500.

45. Moghadam, Z. A.; Mirlohi, M.; Pourzamani, H.; Malekpour, A., Bisphenol A in "BPA free" baby feeding bottles. Journal of Research in Medical Sciences : The Official Journal of Isfahan University of Medical Sciences 2012, 17 (11), 1089-1091.

46. Siracusa, V., Food Packaging Permeability Behaviour: A Report. International Journal of Polymer Science 2012, 2012, 11.

47. The European Commission, Commission Regulation (EU) No 10/2011 of 14 January 2011 on plastic materials and articles intended to come into contact with food Text with EEA relevance. Official Journal of the European Union: 2011; Vol. OJ L 12, pp 1-89.

48. The European Commission, Commission Regulation (EC) No 450/2009 of 29 May 2009 on active and intelligent materials and articles intended to come into contact with food (Text with EEA relevance). Official Journal of the European Union: 2009; Vol. OJ L 135, pp 3-11.

49. PlasticsEurope Explanatory views on Regulation (EU) No. 10/2011 on plastic materials and articles intended to come into contact with food; Plastics Europe: Association of Plastics Manufacturers: 2011.

50. Fu, Y.; Kao, W. J., Drug release kinetics and transport mechanisms of non-degradable and degradable polymeric delivery systems. Expert opinion on drug delivery 2010, 7 (4), 429-44.

51. Spagnul, C.; Turner, L. C.; Boyle, R. W., Immobilized photosensitizers for antimicrobial applications. Journal of Photochemistry and Photobiology B: Biology 2015, 150, 11-30.

52. Jori, G.; Fabris, C.; Soncin, M.; Ferro, S.; Coppellotti, O.; Dei, D.; Fantetti, L.; Chiti, G.; Roncucci, G., Photodynamic therapy in the treatment of microbial infections: Basic principles and perspective applications. Lasers in Surgery and Medicine 2006, 38 (5), 468-481.

53. Decraene, V.; Pratten, J.; Wilson, M., Novel Light-Activated Antimicrobial Coatings Are Effective Against Surface-Deposited Staphylococcus aureus. Current Microbiology 2008, 57 (4), 269. 54. Donnelly, R. F.; McCarron, P. A.; Tunney, M. M.; David Woolfson, A., Potential of photodynamic therapy in treatment of fungal infections of the mouth. Design and characterisation of a mucoadhesive patch containing toluidine blue O. J Photochem Photobiol B 2007, 86 (1), 59-69. 55. Piccirillo, C.; Perni, S.; Gil-Thomas, J.; Prokopovich, P.; Wilson, M.; Pratten, J.; Parkin, I. P., Antimicrobial activity of methylene blue and toluidine blue $O$ covalently bound to a modified silicone polymer surface. Journal of Materials Chemistry 2009, 19 (34), 6167-6171.

56. Sellenet, P. H.; Allison, B.; Applegate, B. M.; Youngblood, J. P., Synergistic Activity of Hydrophilic Modification in Antibiotic Polymers. Biomacromolecules 2007, 8 (1), 19-23.

57. Usacheva, M. N.; Teichert, M. C.; Biel, M. A., Comparison of the methylene blue and toluidine blue photobactericidal efficacy against gram-positive and gram-negative microorganisms. Lasers in Surgery and Medicine 2001, 29 (2), 165-173.

58. Dahl, T. A.; Midden, W. R.; Hartman, P. E., Comparison of killing of gram-negative and grampositive bacteria by pure singlet oxygen. Journal of bacteriology 1989, 171 (4), 2188-94.

59. Health Protection Scotland, National Point Prevalence Survey of Healthcare Associated Infection and Antimicrobial Prescribing 2016. Health Protection Scotland, NHS National Services Scotland, Meridian Court, 5 Cadogan Street, Glasgow G2 6QE: 2017.

60. Demidova, T. N.; Hamblin, M. R., Effect of Cell-Photosensitizer Binding and Cell Density on Microbial Photoinactivation. Antimicrobial Agents and Chemotherapy 2005, 49 (6), 2329-2335. 
61. Decraene, V.; Pratten, J.; Wilson, M., Cellulose Acetate Containing Toluidine Blue and Rose Bengal Is an Effective Antimicrobial Coating when Exposed to White Light. Applied and

Environmental Microbiology 2006, 72 (6), 4436-4439.

62. Donnelly, R. F.; McCarron, P. A.; Tunney, M. M., Antifungal photodynamic therapy. Microbiol Res 2008, 163 (1), 1-12.

63. Weaver, L.; Michels, H. T.; Keevil, C. W., Survival of Clostridium difficile on copper and steel: futuristic options for hospital hygiene. J. Hosp. Infect. 2008, 68 (2), 145-151.

64. Espinal, P.; Marti, S.; Vila, J., Effect of biofilm formation on the survival of Acinetobacter baumannii on dry surfaces. J. Hosp. Infect. 2012, 80 (1), 56-60.

65. Miles, A. A.; Misra, S. S.; Irwin, J. O., The estimation of the bactericidal power of the blood. The Journal of hygiene 1938, 38 (6), 732-749. 